\title{
Laughter Therapy Decreases Depression Among in Senior Citizens Residing in Old Age Homes
}

\author{
Akhil Kumar and Satyajit Patra* \\ American International Medical University, Gros Islet, Saint Lucia
}

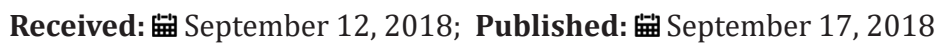

*Corresponding author: Satyajit Patra, Director of Research, American International Medical University, Gros Islet, Saint Lucia

\begin{abstract}
Aging is an inevitable process and many factors like genes, lifestyles, diet and environment determine longevity. As humans go older, physical conditions decline which leads to many illnesses. Depression constitutes the most common emotional disorder found in older people. Estimates of the prevalence of major depressive disorder of the elderly range from $2 \%-10 \%$ of those 65 and older [1]. Depression can be treated by administrating antidepressants, electroconvulsive therapy, Transcranial magnetic stimulations, cognitive behavioral and interpersonal therapies, lifestyle modifications and alternative therapies [2,3]. The alternative therapies encompass a variety of approaches which includes acupuncture, aroma therapy, laughter therapy, biofeedback, chiropractic treatments, guided imagery, dietary supplements, hypnosis, massage therapy, meditation, relaxation and yoga [4]. There is growing empirical literature on the effectiveness of laughter therapy on depression on elderly [5]. The objectives of the study were to compare the mean pre-test depression score of senior citizens between the experimental and control group. We also intended to compare the mean pre-test depression score of senior citizens in the experimental group. The mean pre-test depression score of senior citizens in the control group was compared. The mean post-test depression score of senior citizens between the experimental and control group was compared and evaluated. We also aimed to find out the association between level of depression and selected socio demographic variables of senior citizens in the experimental and control group
\end{abstract}

\section{Methodology}

Research approach was quantitative, and the design used was pre-test/post-test experimental design. The study was conducted in two old age homes and they were allocated to experimental and control setting by simple random (lottery) method. Yesavage Geriatric Depression scale with minor modification was administrated to the inmates of both the setting to identify the client with depression and separate sampling frames were made [6]. Using systematic randomization method, 30 subjects were selected from the experimental setting and 30 from control setting. Laughter therapy was administrated to the experimental group for 30-45 minutes daily for 10 consecutive days. Post-test was conducted using Yesavage Geriatric Depression scale on the 15th day of the therapy.

\section{Results}

The mean pre-test depression score of experimental groups was 16.9 with a standard deviation of 4.0 and that of control group was 16.9 and with a standard deviation of 5.3. While comparing the mean pre-test depression scores of experimental and control groups by independent test, the obtained value was 0.63 which is less than table value 1.67; there are no statistic differences between depression scores of experimental and control groups. This means the two groups are homogenic in terms of mean pre-test depression score. The mean post-test depression score of experimental groups was 1.39 with a standard deviation of 4.4 and that of control group was 17.6 and with a standard deviation of 5.3. While comparing the mean post-test depression scores of experimental and control groups by independent test the obtained value was 2.95 which is greater than table value 2.66 at $P$ value less than 0.01 , rejecting the null hypothesis, so statistically there is significant reduction in post-test depression scores of experimental groups. The mean pre-test depression score of control group was 16.9 with a standard deviation of 5.3 and the mean post-test depression score of control group was 17.6 with a standard deviation of 5.3. The comparison of the mean pre-test and post-test depression score by paired test showed the calculated value as 3.34 which is less than the table value 3.64; hence the null hypothesis is accepted that is there is no significant differences between the pre-test and post-test depression score of the control group. As the control group did not undergone laughter therapy, no change occurred in depression score (Figure 1). 


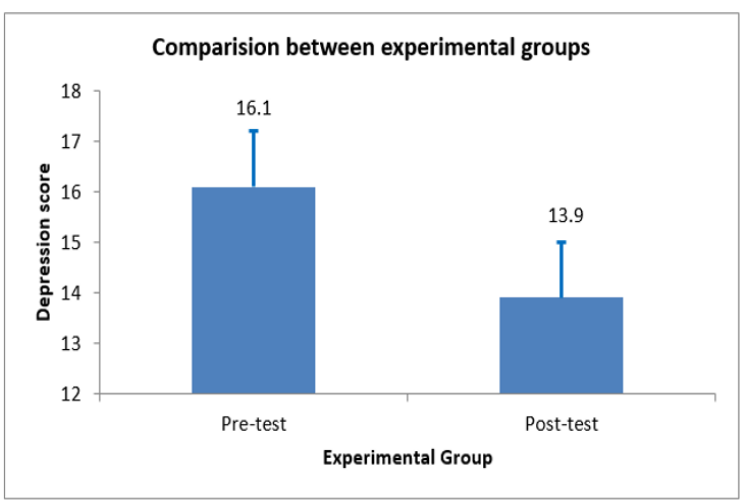

Figure 1.

reduction in the mean post-test depression scores of experimental groups; hence the laughter therapy was an effective treatment for reducing depression.

\section{References}

1. Stubbs B, Vancampfort D, Veronese N, Solmi M, Gaughran F, et al. (2016) The prevalence and predictors of obstructive sleep apnea in major depressive disorder, bipolar disorder and schizophrenia: A systematic review and meta-analysis. Journal of affective disorders 197: 259-267.

2. Haq AU, Sitzmann AF, Goldman ML, Maixner DF, Mickey BJ (2015) Response of depression to electroconvulsive therapy: a meta-analysis of clinical predictors. The Journal of clinical psychiatry 76(10): 1374-1384.

3. Gaynes BN, Lloyd SW, Lux L, Gartlehner G, Hansen RA, et al. (2014) Repetitive transcranial magnetic stimulation for treatment-resistant depression: a systematic review and meta-analysis. The Journal of clinical psychiatry 75(5): 477-489.

4. Pilkington K, Rampes H, Richardson J (2006) Complementary medicine for depression. Expert review of neurotherapeutics 6(11): 1741-1751.

5. Yim J (2016) Therapeutic Benefits of Laughter in Mental Health: A Theoretical Review. The Tohoku journal of experimental medicine 239(3): 243-249.

6. Yesavage JA, Brink TL, Rose TL, Lum O, Huang V, et al. (1982) Development and validation of a geriatric depression screening scale: a preliminary report. Journal of psychiatric research 17(1): 37-49.

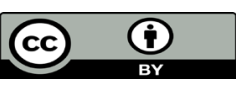

This work is licensed under Creative Commons Attribution 4.0 License

To Submit Your Article Click Here:

Submit Article

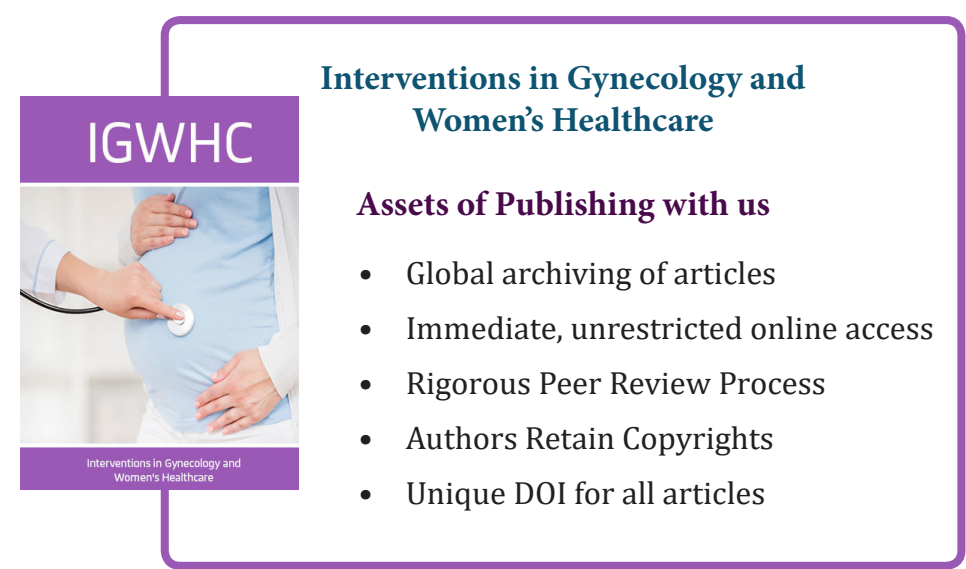

